\title{
Gas Transport Properties and Crystalline Structures of Poly(lactic acid) Membranes
}

\author{
Hideyuki Sawada, Yoichi Takahashi, Sou Miyata \\ Shinji Kanehashi, Shuichi Sato, and Kazukiyo Nagai* \\ Department of Applied Chemistry, Meiji University \\ 1-1-1 Higashi-mita, Tama-ku, Kawasaki 214-8571, Japan \\ Fax: 81-44-934-7906, e-mail: nagai@isc.meiji.ac.jp
}

Gas transport properties (i.e., permeability, diffusivity, and solubility) and the crystallinity/crystalline structure of poly(lactic acid) (PLA) membranes were systematically investigated. PLA membranes with different crystalline structures were prepared by regulating the heating and cooling conditions during their membrane preparation. The PLA membrane that was thermally-treated at $70^{\circ} \mathrm{C}$ was amorphous, while the membrane heated at higher than $80^{\circ} \mathrm{C}$ had crystalline structures. As the treatment temperature increased, the crystallinity increased and the PLA crystal growth branched out in a radial fashion. Regardless of crystallinity, the order of the gas permeability, diffusion, and solubility coefficients was the same for all membranes; permeability coefficient: $\mathrm{H}_{2}>\mathrm{CO}_{2}>\mathrm{O}_{2}>\mathrm{N}_{2}>\mathrm{CH}_{4}$; diffusion coefficient: $\mathrm{H}_{2}>\mathrm{O}_{2}>\mathrm{N}_{2}>\mathrm{CO}_{2}>\mathrm{CH}_{4}$; solubility coefficient: $\mathrm{CO}_{2}>\mathrm{CH}_{4}>\mathrm{O}_{2}>\mathrm{N}_{2}>\mathrm{H}_{2}$. Interestingly, unlike common crystalline polymer membranes, the permeability coefficient in a crystalline PLA membrane was larger than that in an amorphous PLA membrane. The gas permselectivity in the amorphous and crystalline PLA membranes was larger than 120 for $\mathrm{H}_{2} / \mathrm{N}_{2}, 6$ for $\mathrm{O}_{2} / \mathrm{N}_{2}, 23$ for $\mathrm{CO}_{2} / \mathrm{N}_{2}$, and 27 for $\mathrm{CO}_{2} / \mathrm{CH}_{4}$ and less than 1 for $\mathrm{CH}_{4} / \mathrm{N}_{2}$.

Key words: Poly(lactic acid) / Polylactide / PLA / Crystallinity / Gas permeability

\section{INTRODUCTION}

Poly(lactic acid) (PLA) is an environmentally-friendly biodegradable polymer substance. PLA is used as a material in packaging, electronic, and automobile applications. For such applications, oxygen permeability is an important factor to prevent from material degradation (e.g., oxidation), because it is exposed to air during use. The barrier property of carbon dioxide is necessary for a plastic bottle material of carbonated beverage. PLA is expected to use parts for energy gas storage such as hydrogen and methane.

In general, gas permeability, diffusivity, and solubility decrease with increasing crystallinity in a polymer membrane, because gas molecules cannot diffuse and dissolve in the crystalline domain [1].

However, there has been no systematic research on the relationship between gas transport properties and crystallinity/crystalline structure in PLA membranes. PLA is an interesting polymer, whose gas permeability is not significantly affected by its isomer ratio and crystallinity [2]. In the L:D-donor ratio range of 98.7:1.3-50:50 and in the crystallinity range of $0-25 \%$, the oxygen permeability coefficients of the PLA samples were between $1.7 \times 10^{-11}$ and $3.4 \times 10^{-11}$ $\mathrm{cm}^{3}(\mathrm{STP}) \mathrm{cm} /\left(\mathrm{cm}^{2} \cdot \mathrm{s} \cdot \mathrm{cmHg}\right)$ at $30-35^{\circ} \mathrm{C}$. In this study, the gas transport properties (i.e., permeability, diffusivity, and solubility) and crystallinity/crystalline structure of the PLA membranes are systematically investigated.

\section{EXPERIMENTAL}

2.1 Preparation of Membranes

The PLA polymer used in this study was a product code 4032D NatureWorks LLC, Minnetonka, USA.
The ratio of isomer was in the range of $L: D=$ 96.0:4.0-96.8:3.2. PLA membranes were prepared by casting $2 \mathrm{wt} \%$ dichloromethane solution of each onto a flat-bottomed glass Petri dish in a glass bell-type vessel and drying under atmospheric pressure at room temperature. Each solvent was allowed to evaporate for 48 hours. Then, the dried PLA membranes were thermally-treated under vacuum for 48 hours at 70,80 , 90 , and $150^{\circ} \mathrm{C}$ with the dual aims of eliminating the residual solvent completely and obtaining amorphous and crystalline PLA membranes. Afterwards, the thermally-treated PLA membranes were cooled at room temperature under atmospheric pressure. Proton nuclear magnetic resonance ( $\left.{ }^{1} \mathrm{H}-\mathrm{NMR}\right)$ (JNM-ECA500, JEOL Ltd., Tokyo, Japan) and fourier transform infrared (FT-IR) (FT-IR 460+, JASCO Co., Tokyo, Japan) analyses confirmed the chemical structure and the removal of the residual solvent. The thickness of the membranes used in this study varied from 35 to $45 \mu \mathrm{m}$. The uncertainty of each membrane thickness was \pm 1 $\mu \mathrm{m}$.

\subsection{Characterization Analysis}

All characterization data were determined in membrane state for at least three samples in order to confirm the reproducibility of the experimental results. Membrane density $(\rho)$ was determined by flotation of the small membrane samples in a density gradient column, which was maintained at $23 \pm 1^{\circ} \mathrm{C}$.

Wide-angle X-ray diffraction (WAXD) measurements were performed on a Rint 1200 X-ray diffractometer (Rigaku, Co. Ltd., Tokyo, Japan) using a $\mathrm{Cu}-\mathrm{K} \alpha$ radiation source. The wavelength of the radiation was, $1.54 \AA$, and $2 \theta$ was the maximum intensity in a halo 
peak. The crystallinity $\left(X_{C-W A X D}\right)$ was determined based on the percentage of the crystalline area in the WAXD halo.

The thermal analysis data were measured with a Diamond DSC differential scanning calorimeter (Perkin-Elmer, Inc., Shelton, USA). Because these data were used for discussion of gas transport properties, the first heating scan data (i.e., before annealing) represented the optimum condition relative to the second heating scan data. Heat scan was performed from 20 to $200^{\circ} \mathrm{C}$ at a heating rate of $10^{\circ} \mathrm{C} / \mathrm{min}$ under a nitrogen atmosphere. The glass transition temperature $\left(T_{g}\right)$ was determined as the middle point of endothermic transition. The crystallization temperature $\left(T_{c}\right)$ and melting temperature $\left(T_{m}\right)$ were determined as the maximum value of each peak. The crystallinity $\left(X_{C-D S C}\right)$ was estimated by:

$$
X_{c}=\frac{\Delta H_{m}+\Delta H_{c}}{\Delta H_{m}^{0}} \times 100
$$

where $\Delta H_{m}$ and $\Delta H_{c}$ are the enthalpies of melting and crystallization of a polymer $(\mathrm{J} / \mathrm{g})$, respectively, and $\Delta H^{0}{ }_{m}$ is the enthalpy of PLA (L-donor $100 \%$ ) crystal having infinite crystal thickness and a value of $93 \mathrm{~J} / \mathrm{g}$ [3].

The haze value, which is a standard for cloudiness of a polymer membrane, was measured with a haze meter HM-150 (Murakami Color Research Laboratory, Tokyo Japan). The haze value was estimated by:

$$
\text { Haze }=\frac{T_{d}}{T_{t}} \times 100
$$

where $T_{d}$ and $T_{t}$ are the diffused light transmission and total light transmission of PLA membrane, respectively.

The orthoscope observation was measured by using an Olympus BH-2 Polarization microscope (POM) (Olympus Inc., Tokyo Japan) under cross-Nicol condition. Polarization images were observed under an additive color at $530 \mathrm{~nm}$ with a sensitive color plate.

A scanning electron microscope (SEM) was performed with a High Resolution Field Emission Scanning Electron microscopy (FE-SEM) (S5200, JEOL Ltd., Tokyo Japan).

\subsection{Measurement of Gas Transport Properties}

The permeability coefficient $(P)$ of pure gases (i.e., hydrogen $\left(\mathrm{H}_{2}\right)$, oxygen $\left(\mathrm{O}_{2}\right)$ nitrogen $\left(\mathrm{N}_{2}\right)$, carbon dioxide $\left(\mathrm{CO}_{2}\right)$, and methane $\left.\left(\mathrm{CH}_{4}\right)\right)$ in PLA membranes was determined using a constant-volume /variable-pressure method, according to the literature [2, 4]. The operating temperature was $35 \pm 1^{\circ} \mathrm{C}$. The feed pressure was between 75 and $77 \mathrm{cmHg}$ and the permeate side was maintained under vacuum. All permeation data were determined for at least three samples to ensure the reproducibility of the experimental results.

The apparent diffusion coefficient $(D)$ was determined from time-lag $(\theta)$, the period of time needed to reach the steady state:

$$
D=\frac{\ell^{2}}{6 \theta}
$$

According to the solution-diffusion mechanism, the apparent solubility coefficient $(S)$ may be evaluated by Eq. (4):

$$
S=\frac{P}{D}
$$

The ideal permselectivity of Gas $A$ over $B$ was expressed as the ratio of the permeability coefficient of Gas $A$ over that of Gas $B$.

$$
\frac{P_{A}}{P_{B}}=\frac{D_{A}}{D_{B}} \times \frac{S_{A}}{S_{B}}
$$

where $D_{A} / D_{B}$ is the diffusivity selectivity (the ratio of the diffusion coefficients of Gases $A$ and $B$ ) and $S_{A} / S_{B}$ is the solubility selectivity (the ratio of the solubility coefficients of Gases $A$ and $B$ ).

\section{RESULTS AND DISCUSSION}

3.1 Membrane Characterization

The properties of the PLA membranes prepared in this study are summarized in Table 1 . As the thermal treatment temperature increased from 70 to $150^{\circ} \mathrm{C}$, the membrane density increased from 1.257 to $1.273 \mathrm{~g} / \mathrm{cm}^{3}$.

The WAXD patterns in the PLA membranes are shown in Fig. 1. Some sharp halo near to the diffraction angles $15^{\circ}, 16^{\circ}$, and $19^{\circ}$ appeared for the PLA membrane thermally-treated at higher than $80^{\circ} \mathrm{C}$, whereas only a broad halo was observed for the PLA membranes thermally-treated at $70^{\circ} \mathrm{C}$. The PLA membrane thermally-treated at $70^{\circ} \mathrm{C}$ had an amorphous structure, and those treated at higher than $80^{\circ} \mathrm{C}$ had crystalline structures. As the treatment temperature increased, the crystallinity increased from 19.2 to $47.9 \%$ (Table 1). However, the crystalline structures of the crystalline PLA membranes were different from each other, because the position of the sharp halo was slightly shifted with heating.

The DSC thermograms of the PLA membranes during the first heating scan are shown in Fig. 2. Sample preparation conditions of PLA products significantly influenced their thermal properties [5]. In fact, the literature data for PLA membranes showed a wide range of $T_{g}$ values from 55 to $69^{\circ} \mathrm{C}$ [4-11]. The $T_{g}$ values of the membranes were $60.3,56.3,57.1,59.2^{\circ} \mathrm{C}$ for heat treatments at $70,80,90$, and $150^{\circ} \mathrm{C}$, respectively. The data from this study were within the range of the literature values. The literature value of $T_{c}$ for PLA varied from 79 to $118^{\circ} \mathrm{C}$ [4-11]. The $T_{c}$ values of the membranes were $124.2,129.5$, and $124.2^{\circ} \mathrm{C}$ for heat treatments at 80,90 , and $150^{\circ} \mathrm{C}$, respectively. The data from this study were slightly higher than the literature values. The literature value of $T_{m}$ for PLA varied from 149 to $192^{\circ} \mathrm{C}$ [4-11]. The $T_{m}$ values of the membranes were $154.3,154.1$, and $158.1^{\circ} \mathrm{C}$ for heat treatments at 80,90 , and $150^{\circ} \mathrm{C}$, respectively. The data

Table 1 Characterization of poly(lactic acid) (PLA) membranes

\begin{tabular}{ccccc}
\hline $\begin{array}{c}\text { Temperature } \\
\left({ }^{\circ} \mathrm{C}\right)\end{array}$ & 70 & 80 & 90 & 150 \\
\hline$\rho\left(\mathrm{g} / \mathrm{cm}^{3}\right)$ & $1.257 \pm 0.001$ & $1.264 \pm 0.001$ & $1.267 \pm 0.001$ & $1.273 \pm 0.001$ \\
$X_{C-W A X D}(\%)$ & 0.0 & $19.2 \pm 0.3$ & $33.0 \pm 0.2$ & $47.9 \pm 0.4$ \\
$T_{g}\left({ }^{\circ} \mathrm{C}\right)$ & $60.3 \pm 2.1$ & $56.3 \pm 0.3$ & $57.1 \pm 1.1$ & $59.2 \pm 0.3$ \\
$T_{c}\left({ }^{\circ} \mathrm{C}\right)$ & - & $124.2 \pm 0.1$ & $129.5 \pm 0.1$ & $124.2 \pm 0.1$ \\
$T_{m}\left({ }^{\circ} \mathrm{C}\right)$ & - & $154.3 \pm 0.1$ & $154.1 \pm 0.1$ & $158.1 \pm 0.1$ \\
$\Delta H_{c}(\mathrm{~J} / \mathrm{g})$ & - & $-10.4 \pm 0.3$ & $-2.0 \pm 0.1$ & $2.4 \pm 0.5$ \\
$\Delta H_{m}(\mathrm{~J} / \mathrm{g})$ & - & $18.6 \pm 0.5$ & $21.6 \pm 0.2$ & $34.6 \pm 0.3$ \\
$X_{C-D S C}(\%)$ & 0.0 & $8.8 \pm 0.4$ & $21.1 \pm 0.2$ & $39.9 \pm 0.2$ \\
$T_{t}(\%)$ & $94.0 \pm 0.1$ & $93.9 \pm 0.1$ & $93.3 \pm 0.1$ & $93.3 \pm 0.1$ \\
$T_{d}(\%)$ & $0.3 \pm 0.1$ & $4.1 \pm 0.1$ & $29.7 \pm 0.1$ & $48.7 \pm 0.1$ \\
Haze $(\%)$ & $0.3 \pm 0.1$ & $4.4 \pm 0.3$ & $31.8 \pm 0.7$ & $52.2 \pm 0.4$ \\
\hline
\end{tabular}




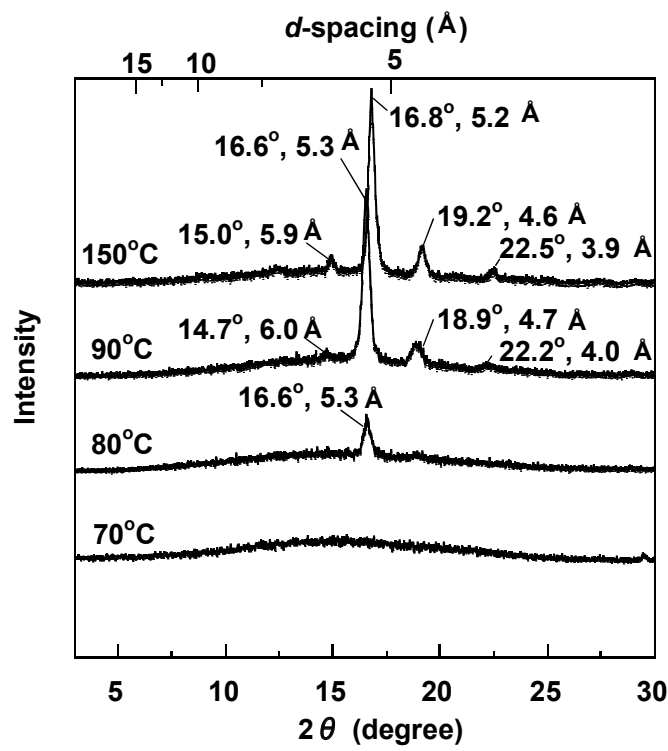

Fig. 1. Wide-angle X-ray diffraction patterns of the poly(lactic acid) (PLA) membranes thermally-treated at $70,80,90$, and $150^{\circ} \mathrm{C}$.

from this study were within the range of the literature values. From the result of the thermal analysis, the PLA membranes thermally-treated at $70^{\circ} \mathrm{C}$ showed an amorphous structure and the membrane thermally -treated at higher than $80^{\circ} \mathrm{C}$ showed a crystalline structure. As the thermal treatment temperature increased, the crystallinity evaluated by Eq. (1) increased from 8.8 to $39.9 \%$ (Table 1 ).

The $X_{C-D S C}$ value of the PLA membrane was $8.8 \%$ at $80^{\circ} \mathrm{C}, 21.1 \%$ at $90^{\circ} \mathrm{C}$, and $39.9 \%$ at $150^{\circ} \mathrm{C}$. As previously mentioned, the $X_{C-W A X D}$ value of the PLA membrane was $19.2 \%$ at $80^{\circ} \mathrm{C}, 33.0 \%$ at $90^{\circ} \mathrm{C}$, and $47.9 \%$ at $150^{\circ} \mathrm{C}$. The $X_{C-D S C}$ value was different from the $X_{C-W A X D}$ value. The $X_{C-D S C}$ value was directly determined with the enthalpy changes, whereas $X_{C-W A X D}$ value was estimated with halo pattern division. Due to this factor, the $X_{C-D S C}$ value had higher accuracy as compared to the $X_{C-W A X D}$ value. However, both WAXD and DSC analyses showed that the crystallinity of PLA membrane increased, as thermal treatment temperature increased.

As is evident from Fig. 3, the PLA membranes were gradually cloudy with increasing thermal treatment temperatures. Regardless of the crystallinity, the $T_{t}$ of all PLA membranes in this study was almost constant value of about $93 \%$. However, as thermal treatment temperature increased, the $T_{d}$ increased from 0.3 to $48.7 \%$. Hence, as crystallinity increased, the haze value increased from 0.3 to $52.2 \%$.

The POM images, which are the standard of dispersion of the crystal domains, are presented in Fig. 3. The PLA membrane thermally-treated at $70^{\circ} \mathrm{C}$ had an amorphous structure, and no crystal domains were observed in the PLA membrane. In contrast, the PLA membranes thermally-treated at higher than $80^{\circ} \mathrm{C}$ had dispersed color variation domains. As thermal treatment temperatures increased, the size of one unit of the color variation domains increased by about $3 \mu \mathrm{m}$ for $80^{\circ} \mathrm{C}, 10 \mu \mathrm{m}$ for $90^{\circ} \mathrm{C}$, and $15 \mu \mathrm{m}$ for $150^{\circ} \mathrm{C}$.

The SEM images in all PLA membranes in this study

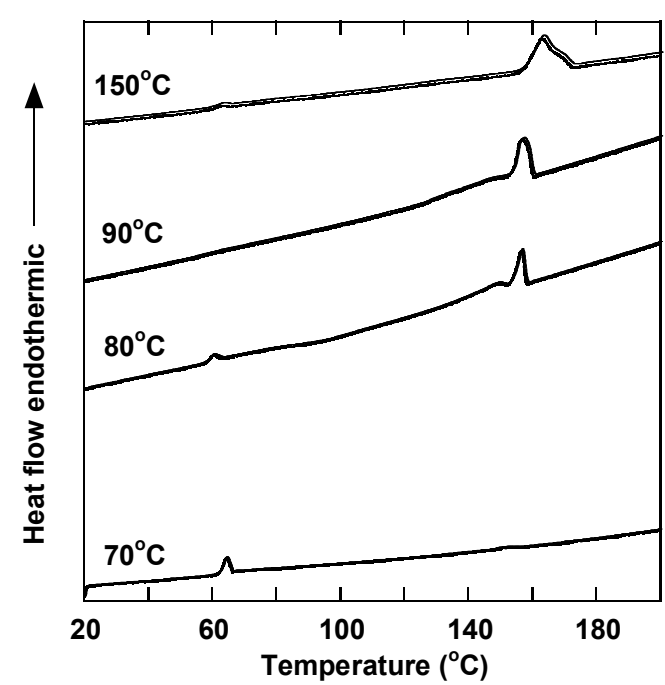

Fig. 2. DSC thermograms of the first heating scan of the poly(lactic acid) (PLA) membranes thermally-treated at $70,80,90$, and $150^{\circ} \mathrm{C}$.

are presented in Fig. 3. A smooth surface was observed in the amorphous PLA membrane thermally-treated at $70^{\circ} \mathrm{C}$. In the PLA membranes thermally-treated at higher than $80^{\circ} \mathrm{C}$, as crystallinity increased, the PLA crystal growth gradually branched out in a radial fashion. The PLA membranes thermally-treated at $80^{\circ} \mathrm{C}$ and $90^{\circ} \mathrm{C}$ had spherical discontinuous units, whereas the PLA membrane thermally-treated at $150^{\circ} \mathrm{C}$ had continuous crystal branches. The size of one unit of the color variation domains in the POM images in Fig. 3 expressed the uneven surface of the branched crystalline structures of the SEM images.

\subsection{Gas Transport Properties}

The gas permeability, diffusion, and solubility coefficients of the PLA membranes at $35^{\circ} \mathrm{C}$ are shown in Table 2. At the experimental conditions used in this study, all PLA membranes were glassy. During the experiments in this study, any hysteresis in the permeation data in all membranes was not observed.

Regardless of crystallinity, the order of the gas permeability, diffusion, and solubility coefficients were the same for all membranes.

- Permeability coefficient : $\mathrm{H}_{2}>\mathrm{CO}_{2}>\mathrm{O}_{2}>\mathrm{N}_{2}>\mathrm{CH}_{4}$

- Diffusion coefficient : $\mathrm{H}_{2}>\mathrm{O}_{2}>\mathrm{N}_{2}>\mathrm{CO}_{2}>\mathrm{CH}_{4}$

- Solubility coefficient : $\mathrm{CO}_{2}>\mathrm{CH}_{4}>\mathrm{O}_{2}>\mathrm{N}_{2}>\mathrm{H}_{2}$

Because the time-lag of hydrogen was shorter, making it difficult to detect with high accuracy, only the maximum prediction value of each coefficient was estimated for comparison.

The order of the gas diffusion coefficient of all PLA membranes was the same as that of gas size such as the gas critical volume: $65.0 \mathrm{~cm}^{3} / \mathrm{mol}\left(\mathrm{H}_{2}\right), 73.4 \mathrm{~cm}^{3} / \mathrm{mol}$ $\left(\mathrm{O}_{2}\right), 90.1 \mathrm{~cm}^{3} / \mathrm{mol}\left(\mathrm{N}_{2}\right), 94.1 \mathrm{~cm}^{3} / \mathrm{mol}\left(\mathrm{CO}_{2}\right)$, and 98.6 $\mathrm{cm}^{3} / \mathrm{mol}\left(\mathrm{CH}_{4}\right)$ [12]. Moreover, the order of the gas solubility coefficients was the same as that of gas condensability such as the gas critical temperature: 304 $\mathrm{K}\left(\mathrm{CO}_{2}\right), 191 \mathrm{~K}\left(\mathrm{CH}_{4}\right), 155 \mathrm{~K}\left(\mathrm{O}_{2}\right), 126 \mathrm{~K}\left(\mathrm{~N}_{2}\right)$, and 33.3 $\mathrm{K}\left(\mathrm{H}_{2}\right)$ [12]. The order of the gas permeability 


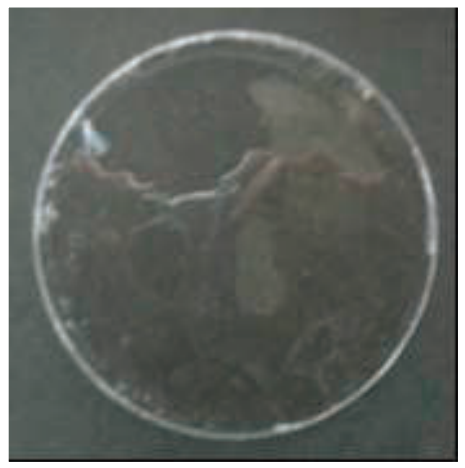

Photo $70^{\circ} \mathrm{C}$

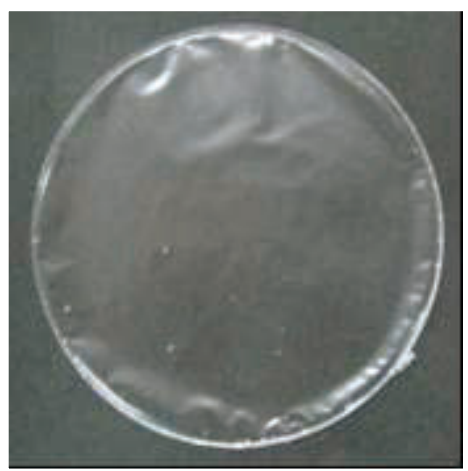

Photo $80^{\circ} \mathrm{C}$

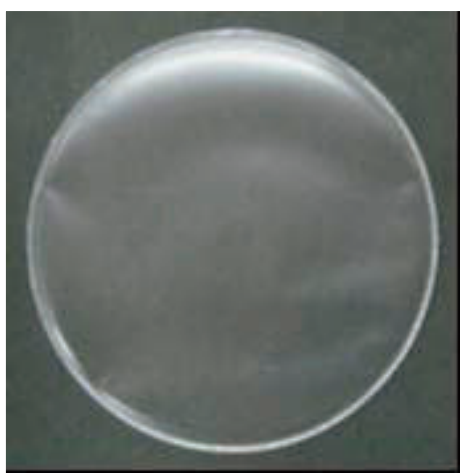

Photo $90^{\circ} \mathrm{C}$

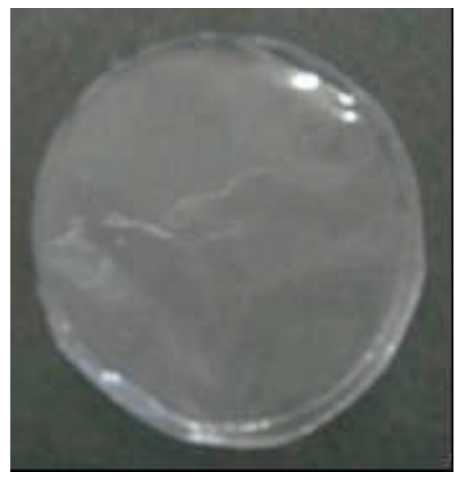

Photo $150^{\circ} \mathrm{C}$

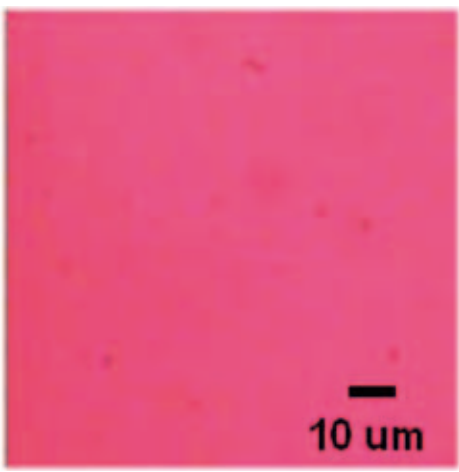

POM $70^{\circ} \mathrm{C}$

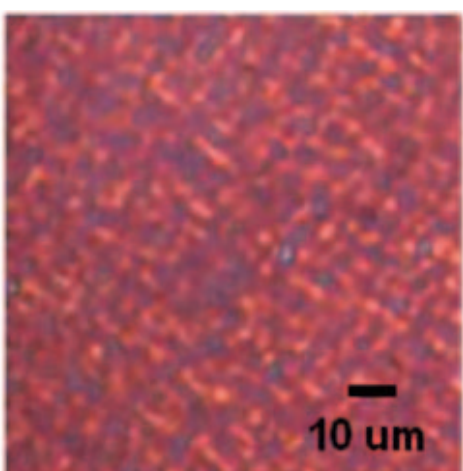

$\mathrm{POM} 80^{\circ} \mathrm{C}$

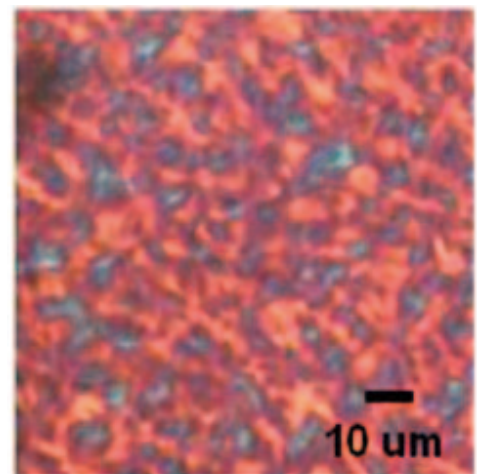

$\mathrm{POM} 90^{\circ} \mathrm{C}$

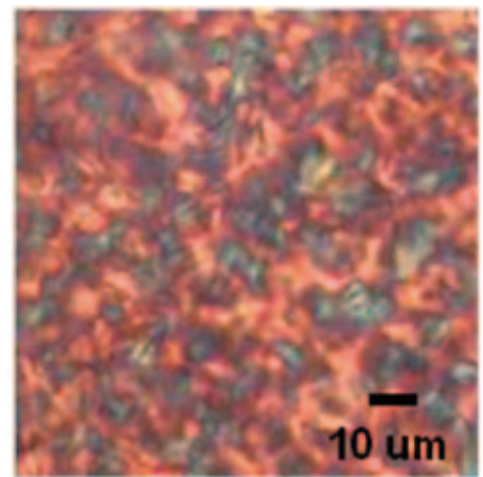

POM $150^{\circ} \mathrm{C}$

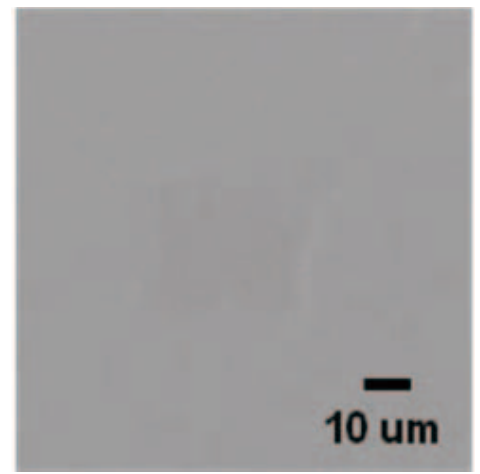

SEM $70^{\circ} \mathrm{C}$

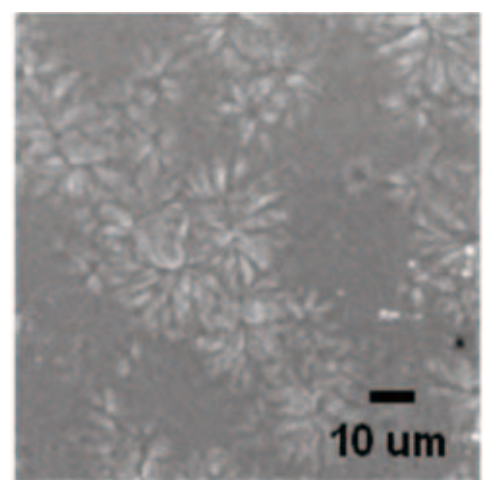

SEM $80^{\circ} \mathrm{C}$

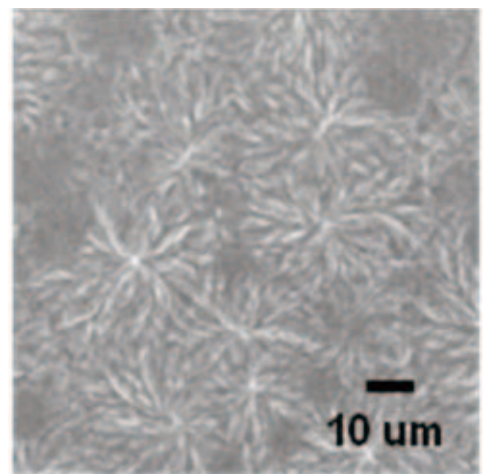

SEM $90^{\circ} \mathrm{C}$

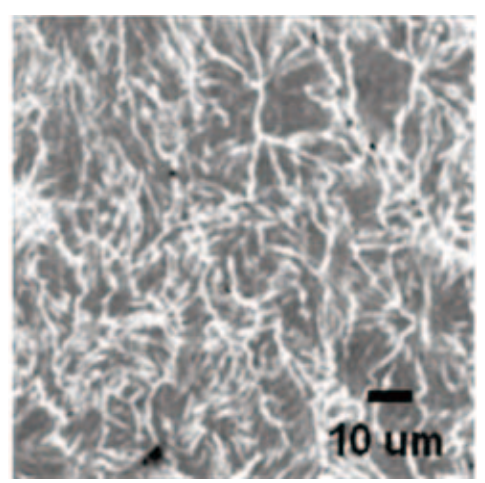

SEM $150^{\circ} \mathrm{C}$

Fig. 3. Photographs, POM, and SEM images of the poly(lactic acid) (PLA) membranes thermally-treated at 70 , 80,90 , and $150^{\circ} \mathrm{C}$. 
coefficient did not follow the gas size and condensability. This result indicates that the gas permeability coefficient of all PLA membranes did not depend on either diffusivity or solubility but on the balance between them.

The gas permeability, diffusion, and solubility coefficients of the PLA membranes as a function of the crystallinity $\left(X_{C-D S C}\right)$ are presented in Fig. 4. With concerning the experimental uncertainties, it is within a small range, but as crystallinity increased, the gas permeability coefficient slightly increased at about $10 \%$ crystallinity. Then, at about $20 \%$ crystallinity, the permeability coefficient showed slightly a higher value as that of the amorphous PLA membrane. Finally, at about $40 \%$ crystallinity, the permeability coefficient was smaller than that of the amorphous PLA membrane. Interestingly, unlike common crystalline polymer membranes, the gas permeability coefficient of the crystalline PLA membrane showed larger gas permeability than that of the amorphous PLA membrane.

Like gas permeability, with concerning the experimental uncertainties, as crystallinity increased, the gas diffusion coefficient increased until about $20 \%$ crystallinity. This is an opposite property of common crystalline polymer membranes, that is, gas diffusivity decreased with increasing crystallinity. Then, at about $40 \%$ crystallinity, the diffusion coefficient was smaller than that of the amorphous PLA membrane. In contrast, as crystallinity increased, the gas solubility coefficient decreased. This result indicates the same tendency as the other crystalline polymer membranes.

In this regard, the reason why the permeability of crystalline PLA membrane was larger than that of the amorphous PLA membrane is that gas permeability coefficient depended more on gas diffusivity than gas solubility.

One possibility is that there might be a continuous space for gas diffusion around the interface between the crystalline and amorphous regions, which might be created by stress of polymer chain arrangements around the interface regions. Then, because the space is larger than the gas molecule size, it is expected to play a role in the bypass of the gas diffusion. Up to about $20 \%$ crystallinity, the spherical discontinuous crystalline units allowed the gas diffusion of such interface and amorphous regions. However, at about $40 \%$ crystallinity, continuous crystal branches appeared. The gas molecules diffused in the bypass interface, amorphous, and crystalline regions. The diffusion route of the gas molecules was completely intercepted, and it is expected that gas permeability and diffusivity decreased.

The gas selectivities of the PLA membranes are shown in Table 3. The gas permselectivity in all PLA membranes was larger than 120 for $\mathrm{H}_{2} / \mathrm{N}_{2}, 6$ for $\mathrm{O}_{2} / \mathrm{N}_{2}$, 23 for $\mathrm{CO}_{2} / \mathrm{N}_{2}$, and 27 for $\mathrm{CO}_{2} / \mathrm{CH}_{4}$ and less than 1 for $\mathrm{CH}_{4} / \mathrm{N}_{2}$. The contribution of the diffusivity selectivity and solubility selectivity of $\mathrm{O}_{2} / \mathrm{N}_{2}$ to the permselectivity were almost the same, whereas the solubility selectivity was a dominant factor in determining the permselectivities for $\mathrm{CO}_{2} / \mathrm{N}_{2}, \mathrm{CH}_{4} / \mathrm{N}_{2}$, and $\mathrm{CO}_{2} / \mathrm{CH}_{4}$.

\section{CONCLUSION}

The PLA membrane thermally-treated at $70^{\circ} \mathrm{C}$ was amorphous, while that treated at higher than $80^{\circ} \mathrm{C}$ had crystalline structures. As thermal treatment
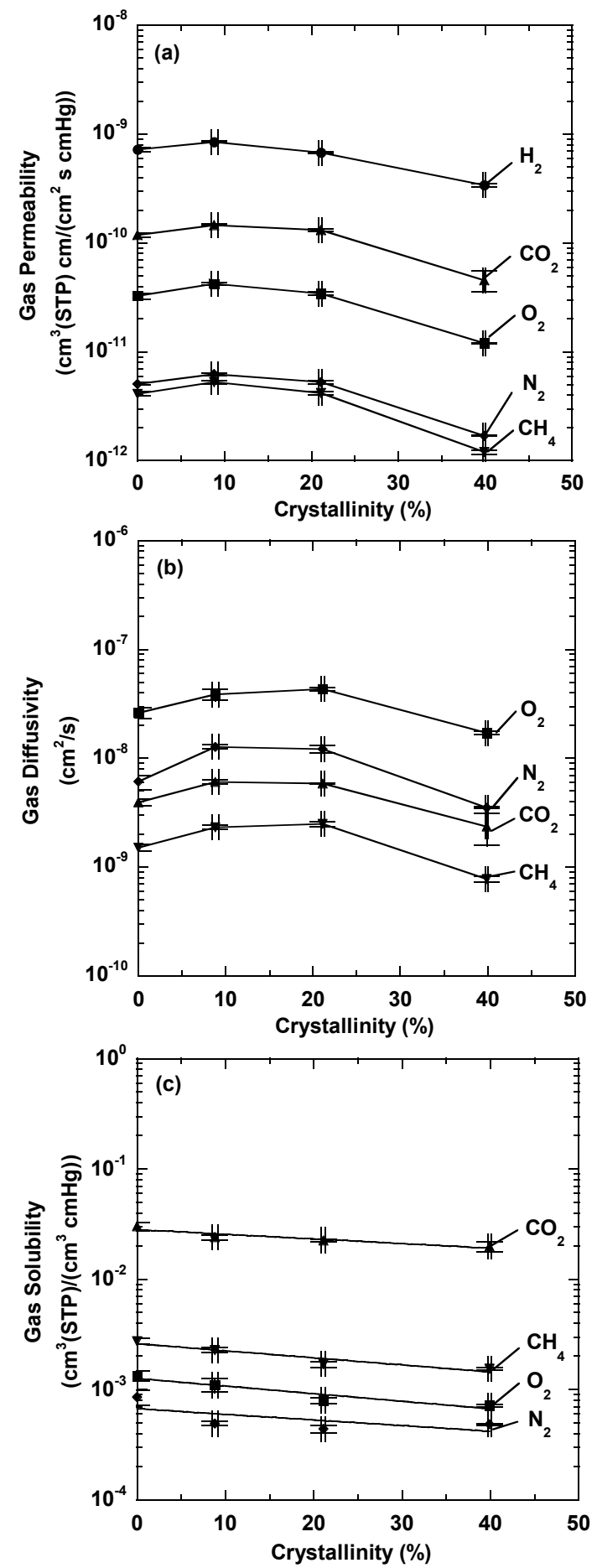

Fig. 4. Effects of crystallinity on the (a) permeability, (b) diffusion, and (c) solubility coefficients of various gases in poly(lactic acid) (PLA) membranes at $35^{\circ} \mathrm{C}$. Gases: Hydrogen $(\bullet)$, oxygen $(\boldsymbol{\square})$, nitrogen $(\bullet)$, carbon dioxide ( $\mathbf{\Delta})$ and methane $(\boldsymbol{\nabla})$.

temperatures increased, the crystallinity increased. For PLA membranes thermally-treated at higher than $80^{\circ} \mathrm{C}$, the PLA crystal growth gradually branched out in a radial fashion. The order of the gas diffusion coefficient was the same as that of the gas critical volume. Moreover, the order of the gas solubility coefficient was the same as that of gas critical temperature. The order of the gas permeability 
Table 2 Gas permeation data of the amorphous and crystalline poly(lactic acid) (PLA) membranes at $35^{\circ} \mathrm{C}$

\begin{tabular}{|c|c|c|c|c|c|c|}
\hline Parameter & $\begin{array}{c}X_{C-D S C} \\
(\%)\end{array}$ & $\mathrm{H}_{2}$ & $\mathrm{O}_{2}$ & $\mathrm{~N}_{2}$ & $\mathrm{CO}_{2}$ & $\mathrm{CH}_{4}$ \\
\hline \multirow{4}{*}{$\begin{array}{l}\text { Permeability } \\
\text { coefficient } \\
\left(\frac{\mathrm{cm}^{3}(S T P) \mathrm{cm}}{\mathrm{cm}^{2} \cdot s \cdot \mathrm{cmHg}}\right)\end{array}$} & 0.0 & $7.23 \pm 0.28 \times 10^{-10}$ & $3.26 \pm 0.21 \times 10^{-11}$ & $5.04 \pm 0.22 \times 10^{-12}$ & $1.18 \pm 0.05 \times 10^{-10}$ & $4.13 \pm 0.17 \times 10^{-12}$ \\
\hline & 8.8 & $8.46 \pm 0.12 \times 10^{-10}$ & $4.21 \pm 0.13 \times 10^{-11}$ & $6.22 \pm 0.12 \times 10^{-12}$ & $1.46 \pm 0.03 \times 10^{-10}$ & $5.27 \pm 0.22 \times 10^{-12}$ \\
\hline & 21.1 & $6.75 \pm 0.12 \times 10^{-10}$ & $3.44 \pm 0.10 \times 10^{-11}$ & $5.27 \pm 0.18 \times 10^{-12}$ & $1.31 \pm 0.03 \times 10^{-10}$ & $4.18 \pm 0.12 \times 10^{-12}$ \\
\hline & 39.9 & $3.40 \pm 0.13 \times 10^{-10}$ & $1.20 \pm 0.01 \times 10^{-11}$ & $1.70 \pm 0.01 \times 10^{-12}$ & $4.53 \pm 0.99 \times 10^{-11}$ & $1.20 \pm 0.05 \times 10^{-12}$ \\
\hline \multirow{4}{*}{$\begin{array}{l}\text { Diffusion } \\
\text { coefficient } \\
\left(\frac{\mathrm{cm}^{2}}{}\right)\end{array}$} & 0.0 & - & $2.61 \pm 0.47 \times 10^{-8}$ & $6.08 \pm 1.44 \times 10^{-9}$ & $3.95 \pm 0.52 \times 10^{-9}$ & $1.51 \pm 0.14 \times 10^{-9}$ \\
\hline & 8.8 & - & $3.85 \pm 0.45 \times 10^{-8}$ & $1.27 \pm 0.45 \times 10^{-8}$ & $6.05 \pm 0.24 \times 10^{-9}$ & $2.31 \pm 0.10 \times 10^{-9}$ \\
\hline & 21.1 & - & $4.33 \pm 0.16 \times 10^{-8}$ & $1.21 \pm 0.09 \times 10^{-8}$ & $5.84 \pm 0.06 \times 10^{-9}$ & $2.48 \pm 0.14 \times 10^{-9}$ \\
\hline & 39.9 & - & $1.71 \pm 0.06 \times 10^{-8}$ & $3.52 \pm 0.06 \times 10^{-9}$ & $2.35 \pm 0.77 \times 10^{-9}$ & $7.76 \pm 0.49 \times 10^{-10}$ \\
\hline \multirow{2}{*}{$\begin{array}{l}\text { Solubility } \\
\text { coefficient }\end{array}$} & 0.0 & - & $1.24 \pm 0.22 \times 10^{-3}$ & $8.28 \pm 2.04 \times 10^{-4}$ & $2.98 \pm 0.41 \times 10^{-2}$ & $2.73 \pm 0.24 \times 10^{-3}$ \\
\hline & 8.8 & - & $1.09 \pm 0.15 \times 10^{-3}$ & $4.89 \pm 0.24 \times 10^{-4}$ & $2.41 \pm 0.12 \times 10^{-2}$ & $2.28 \pm 0.12 \times 10^{-3}$ \\
\hline$\left(\mathrm{cm}^{3}(S T P)\right)$ & 21.1 & - & $7.94 \pm 0.52 \times 10^{-4}$ & $4.36 \pm 0.36 \times 10^{-4}$ & $2.24 \pm 0.07 \times 10^{-2}$ & $1.69 \pm 0.11 \times 10^{-3}$ \\
\hline$\left(\overline{\mathrm{cm}^{3} \cdot \mathrm{cmHg}}\right.$ & 39.9 & - & $7.02 \pm 0.18 \times 10^{-4}$ & $4.83 \pm 0.07 \times 10^{-4}$ & $1.93 \pm 0.20 \times 10^{-2}$ & $1.55 \pm 0.04 \times 10^{-3}$ \\
\hline
\end{tabular}

Table 3 Gas selectivities of the amorphous and crystalline poly(lactic acid) (PLA) membranes at $35^{\circ} \mathrm{C}$

\begin{tabular}{|c|c|c|c|c|c|c|}
\hline Parameter & $\begin{array}{c}X_{C-D S C} \\
(\%) \\
\end{array}$ & $\mathrm{H}_{2} / \mathrm{N}_{2}$ & $\mathrm{O}_{2} / \mathrm{N}_{2}$ & $\mathrm{CO}_{2} / \mathrm{N}_{2}$ & $\mathrm{CH}_{4} / \mathrm{N}_{2}$ & $\mathrm{CO}_{2} / \mathrm{CH}_{4}$ \\
\hline \multirow{4}{*}{ Permselectivity } & 0 & 143 & 6.47 & 23.4 & 0.819 & 28.6 \\
\hline & 8.8 & 136 & 6.77 & 23.5 & 0.847 & 27.7 \\
\hline & 21.1 & 128 & 6.53 & 24.9 & 0.793 & 31.3 \\
\hline & 39.9 & 200 & 7.06 & 26.6 & 0.706 & 37.8 \\
\hline \multirow{4}{*}{ Diffusivity selectivity } & 0 & - & 3.84 & 0.581 & 0.222 & 2.62 \\
\hline & 8.8 & - & 3.03 & 0.476 & 0.182 & 2.62 \\
\hline & 21.1 & - & 3.58 & 0.483 & 0.205 & 2.35 \\
\hline & 39.9 & - & 4.89 & 0.671 & 0.222 & 3.02 \\
\hline \multirow{4}{*}{ Solubility selectivity } & 0 & - & 1.68 & 40.3 & 3.60 & 10.9 \\
\hline & 8.8 & - & 2.23 & 49.4 & 4.65 & 10.6 \\
\hline & 21.1 & - & 1.82 & 51.6 & 3.87 & 13.3 \\
\hline & 39.9 & - & 1.44 & 39.6 & 3.18 & 12.5 \\
\hline
\end{tabular}

coefficient did not follow either the gas size and gas condensability. It was dependent on the balance among diffusivity and solubility. Interestingly, unlike common crystalline polymer membranes, the permeability of crystalline PLA membranes was larger than amorphous PLA membranes. Gas permeability coefficient depended on gas diffusivity relative to gas solubility. One possibility is that there might be a continuous space for gas diffusion around the interface between the crystalline and amorphous regions. The permselectivity for $\mathrm{O}_{2} / \mathrm{N}_{2}$ was dependent on both diffusivity selectivity and solubility selectivity. In contrast, that for $\mathrm{CO}_{2} / \mathrm{N}_{2}$, $\mathrm{CH}_{4} / \mathrm{N}_{2}$, and $\mathrm{CO}_{2} / \mathrm{CH}_{4}$ was more dependent on solubility selectivity than diffusivity selectivity.

\section{REFERENCES}

[1] D.R. Paul, Y.P. Yampolskii, Polymeric Gas Separation Membranes CRC, Boca Raton, 1994.

[2] T. Komatsuka, K. Nagai, Polym. J., 41, 455-458 (2009).

[3] E.W. Fischer, H.J. Sterzel, G. Wegner, Kolloid Z Z Polym., 251, 980-990 (1973).

[4] T. Komatsuka, A. Kusakabe, K. Nagai,
Desalination, 234, 212-220 (2008).

[5] N.A. Weir, F.J. Buchanan, J.F. Orr, D.F. Farrar, A. Boyd, Biomaterials, 25, 3939-3949 (2004).

[6] C.C. Chen, J.Y. Chueh, H. Tseng, H.M. Huang, S.Y. Lee, Biomaterials, 24, 1167-1173 (2003).

[7] E.A.R. Duek, C.A.C. Zavaglia, W.D. Belangero, Polymer, 40, 6465-6473 (1999).

[8] J.H. Lee, T.G. Park, H.S. Park, D.S. Lee, Y.K. Lee, S.C. Yoon, J.D. Nam, Biomaterials, 24, 2773-2778 (2003).

[9] P. Sarazin, X. Roy, B.D. Favis, Biomaterials, 25, 5965-5978 (2004).

[10] H. Tsuji, K. Suzuyoshi, Polym. Degrad. Stab., 75, 347-355 (2002).

[11] F.L. Yao, Y. Bai, W. Chen, X.Y. An, K.D. Yao, P.C. Sun, H. Lin, Euro. Polym. J., 40, 1895-1901 (2004).

[12] B.E. Poling, J.M. Prausnitz, J.P. O'Connell, The properties of Gases \& Liquids, 5th edn, McGraw-Hill, New York, 2000.

(Received January 19, 2010; Accepted March 12, 2010) 